\title{
Josef Niesyto
}

Independent scholar

Azilda, ON, Canada

(D) https://orcid.org/000-0001-8582-8488

\section{Medicine Masks of the Iroquois People as Revealed by the False Faces Society*}

\begin{abstract}
Present-day Iroquois are seeking to preserve traditional healing methods. Members of the False Faces Society routinely perform cleansing rituals using Hodo masks. The spiritual significance and proceedings of the rituals were conveyed by the employees of the Iroquois community center (Longhouse) and the fellow tribesmen gathered around these centers. The participants provided information on the ways of acquiring, crafting, invoking, storage, and honoring the sanctified, animated artifact - the mask. The author of the article confronts the current position of the Onondaga Reserve and the Grand River Reserve Iroquois with historical teachings. The elder generation of Indians has maintained their faith in the mystical power of the rituals, while the secularized new generation approaches them with a strong skepticism.
\end{abstract}

Keywords: healing magic, Iroquois masks, False Faces Society, Hodo, First Nations

Słowa kluczowe: magia lecznicza, maski irokeskie, False Faces Society

[Stowarzyszenie Mylnych Twarzy], Hodo, Pierwsze Narody

Grotesque masks are deeply rooted in the culture of Great Lakes Indians, with their origins dating as far back as ancient times. The masks have survived as an important element of traditional spirituality and are entrenched in currently practiced rituals. What messages did they carry and what significance has survived to this day?

One of the objectives of the recent research which was carried out at the Grand River Reserve and the Onondaga Reserve in Ontario, Canada, was to gather information that would permit the masks of traditional healers to be depicted. For this reason, the masks in the study were cataloged according to

* A self-funded study. The article was based on research conducted as part of author's own work. 
their function, classification and aesthetics. It is worth noting that most common dissemination of knowledge is traditionally done verbally, which plays an important role in native culture.

The majority of the respondents (126) were people over 50 years of age, the middle group of the respondents (97) was aged between 35 and 50 years of age, and the smallest one (43) were young people between 16 and 35 years of age. Much valuable information was provided by members of the group of healers as well as employees of the community center. The number of inquiries performed in the two reserves varied, however, most of the interviews were conducted in the Grand River Reserve. The decision to focus the research in the Grand River Reserve was due to the fact that the area is inhabited by five Iroquois tribes: Onondaga, Oneida, Mohawk, Cayuga and Seneca. The Onondaga Reserve, on the other hand, was chosen because of its historical significance in the Iroquois Confederation (Haudenosaunee). ${ }^{1}$

After compiling all the data collected in the field, the materials obtained permitted the use of comparative analysis method with limited scope of content. Such process allowed for the collection and critical interpretation of photographic data, as well as to explain the useful function of the masks, their classification and aesthetics. The study has also taken into account the religious purpose and use of the masks. Since the Christian community of the Iroquois has retained many customs of the pre-Christian era, the masks of traditional healers have become an actualization of the authentic Catholic religion and elements of traditional religious beliefs and rituals. In order to interpret and clearly explain the religious aspect of the role of the masks, the collected source material has been supplemented with ethnographic literature. In order to better understand the meaning and essence of this cultural phenomenon a phenomenological method has been used.

In 2013/2014 the Iroquois community from the Onondaga Reserve, which has been the subject of the field study, comprised of 498 permanent residents. The Onondaga Reserve is one of a few reserves that can be found on the historical lands of the Iroquois settlement. For this reason, the preserved culture of the healing masks deserved more attention. This tradition is also nurtured in other Iroquois reserves such as the Grand River Reserve.

Among North American Indians masks were commonly used in healing magic. Their owners often united together in various tribal associations, forming a specific group of healers. They performed in full costume on occasions of great tribal celebrations.

Depending on the ethnic group, masks of traditional healers performed two functions. First, they were typically shamanic accessories in ritualistic activities.

${ }^{1}$ Haudenosaunee (hoe-dee-no-show-nee) means "people who build a house." The name refers to a confederation or alliance among the six Indian nations that are better known as the Iroquois Confederation. Each nation has its own identity. 
A healing specialist in such cases was sometimes a bit of a shaman, who by putting on an appropriate costume during a symptomatic dance practices "changed" the outer shell of his personality, by taking the shape of an animal. Usually the healer would dress up as such an animal (e.g., by wearing eagle feathers and decorating feet with claws of this bird). However, this did not take place during the healing sessions themselves, but - as the respondents mentioned - during recurring ceremonies which the healers would take part in as respected members of the community. In the first place, the initiation rites should be named here. Second, in many of the Indian tribes of North America, healers wore masks that depicted the demons of misery from which they were supposed to protect their people or prevent the spread of various diseases, or the diseases they wanted to heal. The masks were worn to scare off the evil spirit who saw the mask on the healer's face and, as a result, fled in fear.

As a rule, therefore, healers' masks looked revolting. They emphasized some kind of flaw in the demon's face or its malicious character - the curved face carved in wood was sometimes an ugly grimace. At this point, we can pose the question: Why did the builders of Gothic cathedrals put carved images of gargoyles on the corners of the buildings? Likewise, the idea was that the evil spirits, seeing their own likeness, would avoid devoted places of worship from afar. Demonic masks, worn by healers, were also supposed to protect them from the undesirable effects of the evil forces they had to face. Similarly, the masks served no different function then the protective gowns worn by European doctors during vaccination campaigns against various epidemics.

The Iroquois can be considered true representatives of the healing masks beliefs and customs. As they settled in the Great Lakes Basin probably in the 16th century the Iroquois are a part of a distinct language identity. Originally, the Iroquois tribes migrated from the south, once settled they found themselves surrounded by vast territorial tribes representing a language of indigenous Algonquin - a group from the eastern part of North America. Therefore, in the 16th century, five Iroquois tribes - Onondaga, Oneida, Mohawk, Cayuga, and Seneca - merged into a defensive coalition and later, in the 18th century, the Tuscarora tribe joined that coalition. This type of union proved to be so durable that in the $17 \mathrm{~h}$ century it began large-scale armed conquests at the expense of the Algonquian tribes, as well as those Iroquois tribes that did not join the League of Five Nations (later, League of Six Nations).

In colonial times, the Iroquois League generally maintained friendly relations with the British, while being a definite enemy of the French and tribes aligned with them. The friendly relations between the Iroquois and the British have determined the alliance that was formed during the American War of Independence. The victorious Americans have driven the Iroquois League and the tribes loyal to the British Crown out of their former territory. The exiled tribes migrated mainly to the opposite side of the St. Lawrence River, present-day 
Province of Ontario in Canada, as well as to the State of Wisconsin in the United States of America. Only a relatively small number of Indians remained - those who fought alongside the Americans or remained neutral during the war. Today, their descendants are Iroquois living in nine reserves in the State of New York.

One of the nine is the Onondaga tribe that settled near the city of Syracuse. During the time of the League of Six Nations, Onondaga enjoyed a central position in the alliance. That position gave them the privilege of periodically holding meetings of the representatives of the Elders of the Six Nations. Also, members of the Onondaga tribe would hold the customary title of the Council Fire Guardians, giving them the status of honorary chieftains of the federation.

The information about the existence of healing masks in the Onondaga tribe dates back to the first accounts of 18th century travelers. In 1743 John Bartram noted:

[...] we were entertained by a comical fellow, disguised is as odd a dress as Indian folly could invent; he had on a clumsy vizard of wood colour'd black, with a nose 4 or 5 inches long, a grinning mouth set awry, furnish'd with long teeth, round the eyes circles of bright brass, surrounded by a larger circle of white paint, from his forehead hung long tresses of buffaloes hair, and from the catch part of his head ropes made of the plaited husks of Indian corn. ${ }^{2}$

The whole bizarre performance made such an impression on the pioneer that in his diary he described the night-time guest as a "goblin" (hobgoblin). ${ }^{3}$ It should be assumed that the chronicler had the possibility of detailed visual inspection of the mask. This occurrence is baffling since a European in the eyes of an Indian healer, was not allowed to have ritual contact with the healing artifact.

\section{Traditional Healers}

The most prominent and best known association of traditional healers among the Onondaga Indians, as well as other Iroquois communities in the USA and Canada, is the False Faces Society. ${ }^{4}$ This association has always been highly regarded by the Iroquois. In most of the reserves, it is the only healer's association that is consistent with the traditional religion, and which still operates and maintains its original function.

${ }^{2}$ J. Bartram: Observation on the Inhabitants, Climate, Soil, Rivers, Productions, Animal, and Other Matters Worthy of Notice, Made by Mr. John Bartram, in His Travels from Pennsylvania to Onondaga, Oswego, and the Lake Ontario, in Canada 1743. London, 1751; Printed from J. Whiston and B. White (reprinted at Geneva, N.Y. 1895), p. 43.

3 J. A. Tuck: Onondaga Iroquois Prehistory. Syracuse University Press, Syracuse 1971, pp. 9-10.

${ }^{4}$ J. Jameson: Narrative of New Netherland (Contains Narrative of a Journey into the Mohawk and Oneida Country. Charles Sribner's Sons, New York 1909), pp. 135-157, 1634-1635. 
The primary task of the Society members is to appease the deities of wind and disease. These evil spirits, in Iroquois beliefs, send pestilence and misery to the people. The Indians were always frightened of them. Even now, as many informants have passed on, some believe in the fatal power of their spells. ${ }^{5}$

It is a common belief that these supernatural beings have no names. However, it should be assumed that their names are not spoken in the local community in order to prevent them from casting an evil spell. Many of the Grand River Reserve older generation informants were convinced that outside of the narrow circle of the initiated the lack of knowledge of these names was due to being simply forgotten by the Iroquois over time. To describe the names of these evil spirits, the synonym "False Faces" is used. In the Onondaga language, the word sounds like "Hodo" and the same word is used to describe the masks that represent these supernatural characters. This was confirmed by all the respondents. These spirits described by Iroquois informants are immaterial, elusive creatures, without bodies, such as humans or animals and without arms or legs, only having faces. Their faces are hideous and terrifying to anyone who looks at them. With their eyes, Hodos have the power to paralyze people who come into contact with them. ${ }^{6}$

The Iroquois believe that evil spirits are still present on their reserves, although it was becoming increasingly difficult to meet a person who would claim to have seen them. ${ }^{7}$ The general impression implied was that the respondents were not completely sure about the existence of Hodo. Among the Iroquois, the incidents of encounters with them are usually mentioned in the third person, adding that it was a long time ago, or not in this, but in another, neighboring reserve. ${ }^{8}$ At the same time, the respondents are of the opinion that it cannot be assumed that these spirits no longer exist, have vanished or simply left. They believe they still exist in the sphere of Indian settlements, but are only deeply hidden. ${ }^{9}$ Citing the elders of the Iroquois community, it should be noted that among the Onondaga, living four to five generations back, it was believed that Hodo lived in a large cave, located in a place far from human settlements. The air surrounding this cave was poisoned and anyone who came close to this cave immediately fell ill. Inside the cave, as it was told, there were carved figures of deities. ${ }^{10}$ Other informants reported that long time ago, hunters hunting in deep forest, far from the campsite, had seen supernatural beings - demons. In the

${ }^{5}$ Information provided by: R. Z., O. from the Grand River Reserve.

${ }^{6}$ J. Hendry: Iroquois Masks and Mask-making at Onondaga. "Anthropolgical Papers" No. 74, Smithsonian Institution, Bureau of American Ethnology, Bulletin 191. Washington 1964, p. 365.

${ }^{7}$ Information confirmed by respondents from the Mohawk tribe from the Grand River Reserve.

${ }^{8}$ Information provided by: R.S., L.A., P.N. members of the Cayuga tribe from the Grand River Reserve.

${ }^{9}$ Information confirmed by all respondents from the Onondaga Reserve.

${ }^{10}$ Information confirmed by older respondents from the Grand River Reserve. 
accounts cited by the storytellers, they encountered demons jumped from tree to tree and their long hair wafted terrifyingly in the wind. ${ }^{11}$

\section{Iroquois Myths and Stories}

There are several myths that refer to the origins of the False Faces Society. The most famous of these myths, which is also passed on to the members of the Society itself, is that the Great Creator fought a duel with the First Hodo to prove to the disobedient spirit who is the rightful ruler of the world. Hodo's claim was that it was him, not the Great Creator, who fashioned the world and gave it life. In the course of the duel, the spirit tried to prove its power by summoning a distant mountain towards himself. After a failed attempt, the Great Creator proceeded. He summoned the mountain and secretly placed it right behind the demon's back. As the evil spirit turned with fury at God's call, he broke his nose by hitting a rock. Then his face twisted in pain. Citing informants, this story is very well known among the Iroquois. ${ }^{12}$

The style of the masks and their facial expressions reflect this mythical incident. The nose, whose grotesque size has already been noticed by Bartram, is often depicted as skewed and broken and the demon's "crooked smile" is in fact an image of his suffering. ${ }^{13}$

\section{Consequences of the dispute}

The Iroquois myth says that Hodo, punished for his pride, must henceforth appear with a disfigured face. The Great Creator, however, was able to turn this misfortune around for the good. Hodo has taught people to make masks in his own likeness, passing on to them the knowledge of how to heal illnesses and keep their misfortunes away. He also conveyed to the people the elements of the ceremony, during which the masks are still presented to the assembly to this day. ${ }^{14}$

Among the Seneca tribe in Ontario, the belief remains that the First Hodo still lives somewhere on the rim of the world, where he takes his giant steps from east to west, walking the path of the sun. Hodo walks with a long staff and carries a huge rattle made from the shell of a mud turtle. As he comes from the

${ }^{11}$ During many meetings with the inhabitants of the Onondaga Reserve, the author had the opportunity to obtain such information.

${ }_{12}$ Information confirmed by all respondents from the Grand River and Onondaga Reserve.

${ }^{13}$ J. BARTram: Observatins on the Inhabitants..., p. 43.

${ }_{14}$ All members of the False Faces Society from the Grand River and Onondaga Reserve were of this belief. 
east his face is red in the morning and black in the afternoon, as he looks back from the direction of the setting sun. ${ }^{15}$

The masks, worn by the members of the False Faces Society, are meant to "scare off" not only the demon, but also to create an impenetrable aura to protect the members of the community from various kinds of diseases. It seems that the purpose of making and storing traditional Iroquois masks becomes understandable only in the context of tribal cosmological beliefs. Masks are the main tool of social cohesion. They are an integral part of the traditional system of native beliefs. Despite the cultural diversity that exists in the League of Six Nations, a number of characteristics of the majority of the Iroquois community and their beliefs can be identified, namely, the concept of essential vital force, present in everything that exists in nature, rocks, animals, women and men, as well as the conviction that this spiritual force connects and enables communication between the sphere of supernatural beings, whose representative in relation to the Iroquois community is Hodo. ${ }^{16}$

The ritual ceremonies of the members of the False Faces Society are understood as a manifestation of the cosmological system through which the Iroquois can establish a beneficial relationship with Hodo and provide themselves and their loved ones with a more secure, ordinary life.

Based on the conviction of informants concerning the role the False Faces masks play in local communities, it can be assumed that they fulfill a similar role to traditional amulets, with the small difference that they are community, tribal based and not individual. For thousands of years mankind has believed and continues to believe in the power of amulets, symbolizing protection from evil and various diseases. The masks of the False Faces existing among the Iroquois, like the amulets in primitive communities, have undergone a gradual metamorphosis in mental, spiritual and physical realm. Successive generations blurred the original meaning and transformed it physically, creating a new, manipulated meaning devoid of power, handcrafted only as works of traditional art. However, the power of the ritual masks of the False Faces lies in the hopes placed in them. In addition, these masks possess the power of social awareness that supports them.

Although there are local variations in the rituals, classifications and styles of the False Faces in the various Iroquois communities, the essential elements of these masks are common to all Iroquois groups. It also appears that they have slightly changed since before colonization. The rituals of the Seneca and Onondaga groups are considered to be the best preserved, and they serve as a model for other communities.

${ }^{15}$ W. Fenton: Masked Medicine Societies of the Iroquois. Smithsonian Report for 1940. Washington 1941, p. 420.

${ }_{16}$ All the respondents from the Grand River Reserve were of the same belief. 


\section{Tasks and Responsibilities of the Society}

In the past, the secret character of the Society was more evident than today. The members performed ex officio and always did so, using traditional masks to cover their faces. Their names were known only to the person coordinating the Society. It was a woman ${ }^{17}$ who was responsible for the storage and safekeeping of the masks secured in the Longhouse, the traditional sacred place of the Iroquois. Both the introduction to the Society and the possibility of leaving it were realized through sleep. Membership in the Society ended when the healer dreamt of leaving the Society. A similar rule applied when it came to the patient's treatment: the patient was suited to begin treatment only once he had a dream of Hodo. ${ }^{18}$

\section{Traditional visits}

With the exception of individual healing ceremonies, False Faces appeared in public three times a year. In spring and autumn, they drove diseases out of the reserves and visited all households. While they were visiting a house, they would start a fire and after that they traditionally sprinkled ashes on the house as a sign of their goodwill. Finishing their visit, they danced. As a token of gratitude, the household members gave them tobacco and corn meal, which they collected in pots. The entire home ritual took place in a playful atmosphere, not only the False Faces were allowed to joke around, so were the members of the families they visited.

\section{Economic Position of the Society}

Gathering tobacco, as a traditional trade activity among the Iroquois, used to put the False Faces Society in an economically privileged position, compared to the entire tribal community. The Society occasionally traded with neighboring Indian tribes. Excess tobacco supplies were traded, be it by sale, donation or exchange.

\footnotetext{
${ }^{17}$ It is a relic of the traditional Iroquois social system in which, apart from the dominant position of warriors, elements of matriarchy coexisted. This information was confirmed by representatives of the older Indian generation from the Grand River and Onondaga Reserve.

${ }^{18}$ Information confirmed by active members of the False Faces Society from the Onondaga Reserve.
} 


\section{The Traditional Costume of False Faces}

When performing a ritual, apart from wearing masks False Faces sometimes wore old, tattered clothes. Occasionally, to make themselves look even more grotesque, they would stuff various objects underneath the clothes, for example, pans (it was this kind of outfit that made Bartram so amused). When performing the dance, as well as when crossing from house to house, each representative of the Society - in the likeness of the First Hodo - carries a rattle made from a turtle shell, as well as a staff to which miniatures of masks are attached.

\section{New Year celebrations}

A third way False Faces can be seen in the public is during their performance at the New Year celebrations. For this customary occasion the local community gathers in the traditional Iroquois Longhouse (community house). This celebration is presided over by members of the False Faces Society. At the beginning of the annual celebration, in an appeal one of the members asks Hodo, on behalf of the whole community, to take away the diseases with which he has been oppressing the people over the last year. After the invocation is said, he traditionally blows into the ashes as a sign that Hodo has taken away all the diseases and simultaneously signals to the community to offer the members of the False Faces tobacco in return. After the ritual of blowing into the ashes it was time for traditional dances accompanied by rattles and drums. ${ }^{19}$

From the moment the ceremony starts, several members of the Society acting as the Door Guardians begin to guard the door, so that none of those present will discreetly leave the celebration. The presence of all members of the Society is compulsory and they are required to participate in performing common dances. Those who refuse to participate in the dances are being knocked to the floor by other members of the Society and as a punishment are rubbed with ash, symbolizing the diseases of the past year.

The effectiveness of traditional rituals are largely determined by the personal talent of the individual and their performance. ${ }^{20}$ It seems, however, that the very name "False Faces Society" is somewhat misleading, as it suggests that to the participants and performers of these rituals these practices are merely to imitate and entertain. Perhaps today, in the era of ubiquitous secularization, which came about as a consequence of the technological evolution, it is virtually the case in many such instances. Nonetheless, the members of local False Faces Societies take the ritual-enacted activities very seriously. From the moment of donning

\footnotetext{
${ }^{19}$ Information confirmed by employees of the community center, called the Longhouse, in the Grand River Reserve.

${ }^{20}$ W. N. Fenton: Masked Medicine..., p. 422.
} 
the masks, the members behave as if they really believed they were superhuman beings and in a way, experienced a personal transformation. It even happens that while performing a ritual dance they may enter into a trance. ${ }^{21}$

\section{Sculptors and Masks}

In the olden days, the very activity of carving the mask had a religious character. Many older sculptors recalled that the artist who carved the mask was subjected to various demands and restrictions, such as, sexual restraint, both before and after the process of crafting the mask.

The masks were carved from the trunk of a living tree, so that they would continue to live, like the mythical World Tree - an Iroquois symbol of peace and unity. The Iroquois usually used linden tree to make the masks because the fiber of this tree absorbs moisture and there is also a belief that this tree had healing properties. ${ }^{22}$

The sculptor, having chosen the right tree, knelt at the roots of the tree and ceremonially smoked tobacco. After that he would tell the people around him the legend of the First False Face and ask the tree in the traditional prayer to entrust its life to him. Then, with an axe, he marked the shape of the future mask on the tree trunk. The chosen block of tree would then be separated from the trunk with the final decisive strikes of the axe.

Several informants, engaged in the traditional making of artistic masks, were convinced that if a sculptor manages to get a whole, unbroken piece of wood, and at the same time the tree will remain untouched, it means that the linden tree placed its life in the hands of a man. Such ceremonial activities initiating the carving of the masks are currently not practiced by Iroquois sculptors. They believe that the mask achieves its healing ability after all the purely technical tasks around mask-making are finished.

The sculptors, however, still observe the traditional ceremony named "Becoming a healer," which is performed immediately after the mask is created. It involves smoking tobacco for the first time around the mask. The purpose of

${ }^{21}$ Information provided by: L.P., D.A., Z.E., R.T. Cayuga Indians from the Grand River Reserve. From the point of view of North American Indians, the boundaries between the world of spirits and the world of living people were not clearly defined, because they were separated by a third, transitional world. A man, who had the right power or performed the appropriate rituals (as did the members of the False Faces Society among the Iroquois from the Great Lakes) could undergo transformation into some being and, as a result, be perceived as its real embodiment. The Indians of the Kwakiutl tribe and Haida from the North West coast believed that supernatural beings who created the world in the early times often take the form of animals or humans. In some dances, expensive wooden masks were used to illustrate this transformation. See. C. LÉvi-STrauss: Drogi masek. Łódź 1985.

${ }^{22}$ Information confirmed by local sculptors from the Onondaga Reserve. 
the smoke is to purify the mask. The next stage of the ceremony is to attach to it a bag filled with tobacco. Only after this action has been completed, a magical phrase is spoken over the finished work. ${ }^{23}$

In the view of the informants who were willing to provide this information, the mask acquires the healing power after such a ceremony and becomes a sacred object that is used by the False Faces Society during the healing ritual.

\section{Healing Capabilities of Masks}

The Iroquois believe that a distinct spirit lives within the mask, whereas the mask itself lives thanks to a life given to it by the "maternal" linden tree. Masks kept in the ritual house should be fed regularly with corn meal. Authorized individuals check on regular basis if the masks are kept in dignified conditions. The caretakers have indicated that it is their duty to speak to the masks and routinely wipe their surfaces with wood-preserving sunflower oil.

Much of the information about the storage of the masks has been provided by the employees of the community center. According to them, it is essential to put the mask face down after performing the healing activities. Placing it in the opposite direction, face up, means summoning its death. From all the respondents asked, such an improper placement of the mask is considered to be an act of insult to a sacred object.

By placing the mask face down it is inherently neutralized, that is, the mask loses its power and is incapable of harming anyone. Furthermore, it is unable to initiate contact with Hodo inhabiting the mystical dimension. There is a common belief among the Iroquois as to how to approach masks hung on the wall. The masks should face the wall or be covered so that they do not influence people who happen to be in their gaze.

Only a small number of elderly informants were convinced that some masks are said to have the power to warn their owners about an imminent illness or death. Some of the respondents residing in the Onondaga Reserve, in support of this claim indicated that this ability manifests itself through perspiration on the surface of the mask, or the mask falling down from the wall by itself. Also, the masks sometimes react by speaking directly to the owner. ${ }^{24}$

Among all the Iroquois tribes, there is a belief that the events that took place in one of the reserves in the Seneca tribe in the mid-20th century are true. The tale being told is about one particular mask held in storage, which was said to be

${ }^{23}$ Information E. R., N.O., L. M., S.T. from the Grand River Reserve.

${ }^{24}$ Information from employees of the community center, Longhouse, from the Grand River Reserve. 
able to "contact and lecture" more recent, newer masks. Due to this extraordinary ability, it was kept in a separate location, away from other masks. ${ }^{25}$

The Iroquois still believe that each mask retains its individual personality. In most cases it is a capricious personality. Masks are apparently always in a bad mood and people find it difficult to please them. Indians often call them "poison" because they cause their owners anxiety and various problems. Masks can be tamed by frequently nurturing and wearing them. An alternative way to tame the masks are sacrifices, that is, placing tobacco in a location above which the specific mask hangs.

The informants, who had the obligation to take care of the masks in the local community center, firmly stated that people mocking the masks or talking to them without due respect will face a punishment. That punishment can manifest itself in the form of illness, but would most often be in the form of spasms that cause facial deformities. Such afflictions can only be cured during a healing ceremony using that particular mask. Moreover, in order to alleviate its anger it was necessary to offer it a large quantity of tobacco. ${ }^{26}$

\section{Mask Aesthetics}

The mainstream aesthetics of Iroquois seems to be avoiding healing masks. It is even difficult to talk about a style, which is common with the rest of the tribe's artistic activity. Iroquois cultural products such as bowls, spoons, etc. are characterized by simplicity of style, while the magical masks have a refined form and reveal attention to detail. Such differences may suggest that the healing masks of the Iroquois have copied or adapted the ascetics from another tribe's culture. ${ }^{27}$

Jean Hendry, researching among the Onondaga tribe in the 1950s, believes that this is not necessarily the case. An equally sensible explanation is the relationship between form and function. Any portrayal of Hodo being powerful and

${ }^{25}$ Information confirmed by all the respondents.

${ }^{26}$ Information provided by N.A., P.H., F.O. from the Grand River Reserve. The history of tobacco usage is as old as human history. On the North American continent among indigenous peoples, there is no community in which tobacco would not form element of cultural identity.

${ }^{27}$ Whenever we have the opportunity to see the masks of the Iroquois Indians, the same question arises: Why these bizarre hair, eyes, or a tilted nose are a permanent feature in all types of masks? The questions will remain unanswered until we realize that, like Indian myths, masks cannot be interpreted by themselves - as isolated artifacts. The myth does not show meaning only from the point of view of the content itself, it acquires this sense only by placing it in some cultural group. Similarly, one type of Iroquois mask analyzed visually may be similar to other types, because it is a transformation of their contours and colors, thereby gaining its originality. Therefore, one can speak of assimilation of certain characteristics from another tribe. See C. LÉvi-STRAUss: Drogi masek..., p. 10. 
dangerous must reflect the attributes of these creatures, so it is obvious that the masks should have an emotional character that is not found in sculptures used in less dramatic circumstances. ${ }^{28}$ This argument can be regarded as convincing, although the heterogeneous hypothesis of the origin of the healing masks within the Iroquois is not without merit either.

Notwithstanding the differences of some detail, all Hodos have some common features. The sculptures have deep ridges and the facial features, although clearly human, are always distorted or caricatured. The eyes are deeply embedded and surrounded by strips of sheet metal (this detail also fits in the 18th-century description quoted above), an elongated nose with a high and sharp bridge that can be bent in one direction (a reflection of the broken nose of the First Hodo). An even more distinctive feature of the mask are the lips, which can be freely bent, removed, skewed, or expanded. The lips can also be formed into a smile and often, protruding teeth or an extended tongue are added. Hodos faces usually exhibit deep wrinkles around the mouth or eyes and some of the masks have a sculpted comb made of bone on the forehead or nose. Horse hair, white or black, is attached to the skull and is hung in the form of two long curls. The masks are usually painted either black or red, but rarely both at the same time. If both colors are used, they are separated by a vertical line running along the center of the face.

A different style of masks, are healing masks made from woven corn husks. They symbolize the three spirits of harvest whose epiphanies are corn, beans and squash. The three spirits have taught the people to grow these crops. These masks are much less common than those made of wood. The members of the healing association who wore them have since passed on in the middle of the last century, without recruiting new members. In the Onondaga Reserve, however, several such masks are still used for healing purposes in the rituals of the False Faces.

In addition, there are also masks representing animals: bears, pigs or birds. These are naturalistic depictions. According to informants from the Grand River Reserve they may have originated from ancient healing associations that ceased to exist in the early colonial period. ${ }^{29}$

Jean Hendry was of a similar opinion on this subject, complementing the information provided by the respondents with the fact that not all of the masks had healing functions - for example, deer skin masks were used to frighten disobedient children. The above statement seems very likely.

\footnotetext{
${ }^{28}$ J. Hendry: Iroquois Masks..., p. 368.

${ }^{29}$ Ibid., p. 369.
} 


\section{Classification of Masks}

The early researchers recorded many different types of masks. Even Harriet Converse, who in $1892^{30}$ was admitted to one of Seneca tribe's healing associations, gives them names according to their usage: Live, Doctor, Wind, Scalp, Clan, Harvest, Maternity, Night, Completing and Counselor.

However, Harriet successors in research of the Iroquois ${ }^{31}$ do not corroborate such a multiplicity of categories, citing only four different types: Doctor, Doorkeeper, Beggar and Dancer. The first two of the four represent the most revered masks, symbolizing the very first False Faces. For this reason, they play a key role in healing rituals. Mask of a Beggar, which refers to a person who collects tobacco donations, represents the so-called Faces of the Forest and, according to the Iroquois, is less powerful. Masks with warped lips and a crooked nose, with a dense network of wrinkles are the most common examples among the False Faces. They are used by Healers and Door Guardians during ceremonies. The Onondaga tribe often features expressions of faces with their tongue outstretched, while those bearing a comb on their forehead are typical of the Seneca people.

A specific group of masks are the "smiling" masks, with thick lips and drooping cheeks, mostly used by Onondaga. These masks are also known as "whistling masks" because their users whistled during the ritual dance. The masks with faces separated by a vertical line symbolize "a god whose body is torn in two," 32 one half belonging to the human world and the second half to the spirit world. These masks are rare (found at the Grand River Reserve in Ontario) and are not known in most Iroquois communities. They may have been adopted from one of the neighboring tribes, during a period of forced migration and growing interactions at the turn of the 18th and 19th centuries.

A certain mystery for ethnographers are "blind" masks, namely, masks with no eyes. They were originally used in the rituals of only one healing society. Allegedly the person wearing them displayed the ability to find hidden items. However, these masks have not been in use since the middle of the 19th century. The Onondaga Indians, while providing information to researchers in the next century, avoided revealing any knowledge about these masks.

${ }^{30}$ H. M. Convers: Myths and Legends of the New York State Iroquois. University of the State of New York, Albany 1908.

${ }^{31}$ According to Fenton, Doctor and Doorkeeper masks are the most sacred and take the leading parts in the curative rituals as they symbolize the First False Face. Those of the Beggar class represent the Common Faces of the Forest and are less powerful though they are also used for curing. Secret masks never appear in public ceremonies; their function and symbolism are unknown.

32 J. Hendry: Iroquois Masks..., p. 370. 
Despite the fact that some of the Iroquois attribute more power to blackcolored masks and others to red-colored masks, most Indians believe that the colors of the masks do not have any significant role in rituals.

\section{Social Status of Masks}

The status of the mask increases with its age. The more times it is used, the more rites it passes; the more people it heals, the more it is valued, worshiped and revered. Therefore, masks that do not differ from each other in appearance, but have different functions, can, like people, "advance" with time. Respondents from the Grand River Reserve recalled cases known to them from the Onondaga Reserve when, for example a "Beggar" mask transitions to a "Doctor" or a "Doorkeeper" category. According to them it is a normal transformation that occurs amongst sacred objects which are the False Faces Masks.

However, the information about the aesthetics of the Iroquois healing masks are very scarce. It is based on observations made in the period when the Iroquois assembled in reserves were strongly influenced by acculturation, both in the internal, inter-tribal perspective and in the field of interactions with other tribes. A further difficulty is presented by the material that was used and its susceptibility to deteriorate.

As Hendry recalls (one of the first researchers on the subject at the Onondaga Reserve), she did not find masks older than one hundred years old, ${ }^{33}$ and even those found were a great rarity, as masks had previously been destroyed by Christian missionaries and Indians themselves. Moreover, it is difficult to assess the age of a mask on the basis of sculpture itself, as many contemporary masks imitate older artifacts.

Nonetheless, there seems to be a general trend among mask-making. The first generations of masks were created in the likeness of the First Hodo, rendering in detail his painfully twisted face and broken nose. Later sculptors (the 19th century) deviated from this template, concentrating instead on individual afflictions of people healed with the masks.

The design of healing masks has also been influenced by contact with the Europeans. Although there are no artifacts representing the earlier period, it is known that the original masks were created by means of burning and scraping the wood. When French explorers and trappers brought with them metal tools at the beginning of the 17th century, it must have revolutionized the traditional sculpting techniques. One can assume that the very operation of sculpting with these tools became easier, making the masks more refined and subtle. As an

\footnotetext{
${ }^{33}$ Ibid., p. 371.
} 
example of this innovation can serve the visage of a face with a drooping lip and open-movable mouth.

Around the beginning of the twentieth century, masks have been clearly influenced by the stylistic patterns of the white man. An example of such an influence are the masks of faces with horns that evoke resemblance to European beliefs in the Devil.

\section{The Religious Aspect of Mask-Making}

In many ways, False Faces seem to serve the same purpose, as today they also evoke feelings of fear and command respect, just like they used to do in the culture of the indigenous people. Official characteristics of the healing rites have been preserved till today, the mythological and religious concepts underlying these rites are still known, and mask users generally follow traditional rules for their storage.

Many respondents from the Grand River and Onondaga Reserves recalled miraculous healings caused by certain masks or the extraordinary abilities of other masks. This information is kept by the Indians in the Community House, as evidence of the supernatural properties of the sculptures. Records of their wicked abilities are kept as well, illustrated with stories of what happened to people who offended them.

One informant mentioned a man whose face became skewered because he was mocking one of his masks. Another person, working in the community center, spoke of the case of a woman who suffered convulsions as she was making fun of members of the False Faces Society.

\section{Storage of masks}

The masks currently worn by members of the healers' association are kept together in a room called the "Hodos' Room" in the local community center. The majority of them were made for the Winter Solstice and all were fabricated in the traditional way by the members of the False Faces Society. The masks were placed face up on the floor of the community center and surrounded by tobacco smoke. Every mask has a bag of tobacco attached and bears signs of being fed corn meal. The zeal of the Indians in following the imposed rules applies even to those masks that are not in their possession. 


\section{Belief in the extraordinary healing power}

Among sculptors, traditional False Faces masks are highly respected. Many informants mentioned the local folk sculptor Allison Thomas, who along with his colleagues - Iroquois sculptors, occasionally organized excursions to the museum in Alban to honor the ancient masks. He did so because, as he used to say, "for many years the masks had been neglected, one should speak to them and apologize by offering them tobacco." ${ }^{34}$ Such a visit to the museum testifies to his deep faith in the extraordinary healing power emanated by the masks. ${ }^{35}$

\section{A new manipulated dimension of masks}

Nevertheless, despite the declaration of faith and scrupulous observance of traditional customs, there is evidence that old beliefs have lost their validity or have changed. Only a handful of informants mention the supernatural beings that the masks represent. Such neglect may be due to an unwillingness to provide information about the sacred nature to strangers, rather than to a lack of knowledge. As noticed, the informants were more willing to talk about the religious uses of the masks.

Those few respondents who mentioned Hodo by name used the past tense. They said that Hodo lived on the edge of the reserve, that they were sometimes seen in the forest, that older people dreamed about them - always suggesting that it was the past. A young sculptor quite openly expressed his doubts about the existence of these spirits, as he never saw them, even though he explored every part of the reserve. The same man has also openly expressed his doubts about the effectiveness of the rituals of the False Faces. He mentioned a ceremony that his parents prepared for him when he was a child, and ended his story as follows: "I did indeed get better, but of course I had been feeling ill for a long time and, eventually, I had to recover." ${ }^{36}$

\section{Fear of carved masks}

A very small number of informants emphasized the fear that can accompany people watching or touching the masks. The research showed that this group was made up of younger women. The respondents also mentioned that Allison Thomas's wife was terribly afraid to be alone in the community center where the masks were kept. She thought she heard the masks talking to her at night and

\footnotetext{
${ }^{34}$ Information provided by many of the respondents of the older generation and confirmed by the staff of the ethnographic museum in Alban (Ontario).

${ }^{35}$ Information confirmed by employees of the ethnographic museum in Alban (Ontario).

${ }^{36}$ Information K.R. from the Mohawk tribe.
} 
believed that they were the ones that brought about a blizzard that occurred one winter. Several other women called the masks "horrible" and said that they were dreadful, but it seemed that their reaction to the symbolism of the masks was not so much inherent but more feminine, due to the grotesque appearance of the sculptures. Older women, just like men, had a different perspective towards these extraordinary artifacts. They showed no fear or concern when they were beside the masks.

Given the likelihood that belief in the supernatural spiritual powers of the False Faces is no longer authentic and unconditional, there are obvious indications that some of the practices and beliefs have been borrowed recently, or at least have been established through external influences. Nowadays, members of the False Faces Society, and specifically sculptors, have access to literature relating to Iroquois masks and rituals, for example, by William N. Fenton and Pete Hest. Their curiosity and awareness of these ethnographic works was reflected in the interviews. One of these men reported that although nowadays in Onondaga the masks are called Hodo, their real name is Gagohsa (a Seneca term). This is true because this information must have been taken from the ethnographic literature.

Another informant, a folk sculptor, pointed out a distinct form of classification for the masks. He explained that the Onondaga tribe, of which he is a member, does not classify these masks by category: Doctor, Doorkeeper, Beggar and Dancer, because it is a classification used by the Seneca tribe. It is to be assumed that the artist has taken such information from literature, for instance, the work by Clark Wissler - The Lore of the Demon Mask. ${ }^{37}$

It is highly likely that sculptors making traditional masks drew a lot of inspiration for "new ideas" from this type of ethnographic work and various other studies. This hypothesis was confirmed by many sculptors. They admitted that in the collection by Pete Hest, they found many suitable artistic forms for making masks. He himself, not being an Iroquois, encouraged folk artists to continue the art of sculpting masks and cautioned them not to sell ritual masks or let white people desecrate them by taking pictures of them.

\section{Preservation of tribal tradition}

A significant role in preserving the tribal tradition among the Iroquois (residing in reserves in the province of Ontario, Canada) is carried out by the False Faces Society. Its members are both experts, teachers and guardians of traditions in the local communities. It is because of their initiative that many community centers have formed groups of ten to twenty people who gather on winter evenings to cultivate their traditions. The meetings regularly take place in the room where the masks are hung. During such meetings they have a meal

${ }^{37}$ C. Wissler: The Lore of the Demon Mask. Natural History, New York 1928 (4), pp. 339-352. 
together, customarily a corn soup, learn traditional songs from the elders and become familiar with Iroquois folklore.

It is difficult to judge to what extent Pete Hest, a researcher and a connoisseur of the masks of the False Faces Society, is directly responsible for the survival of the Society itself among the Iroquois. He was undoubtedly an important figure in shaping the attitudes and activities of the young generation. One of the informants recalled a statement made by a young man during the researcher's stay in the reserve: "If Pete Hest's not ashamed to act like an Indian, we shouldn't be ashamed either." 38

The conducted interviews made it possible to demonstrate to the local community the authentic interest in Iroquois ethnography among Polish researchers. The field research that was conducted by the author was to some extent a continuation of the research started by Pete Hest.

\section{Conclusion}

On the basis of the research carried out, one can put forward a hypothesis that in the culture of the Iroquois the Masks of False Faces are undergoing a gradual metamorphosis in the intellectual, spiritual and physical realm. The outside influence of modern technological culture upon traditional beliefs and objects of worship, such as masks, is blurring the fundamental meaning and symbolism of these sacred artifacts. Furthermore, the present sculptors of the masks are altering them physically, establishing a new perspective that deprives them of the capacity to heal.

The presented material does not allow for a clear account of the attitude of present-day Iroquois towards the masks. The assessment of one's beliefs is always difficult, especially in this case. However, the very fact that most elders do not wish to talk about the masks and their rituals with outsiders suggests that they may still believe in the healing power of the sculptures, while the beliefs of the younger generation have already been gradually transformed.

The collected data show that the majority of contemporary Iroquois society makes a conscious effort to uphold traditional beliefs and customs.

${ }^{38}$ Information provided by the guardian and animator of traditional culture in the Grand River Reserve. 


\section{Bibliography}

Bartram J.: Observation on the Inhabitants, Climate, Soil, Rivers, Productions, Animal, and Other Matters Worthy of Notice, Made by Mr. John Bartram, in His Travels from Pennsylvania to Onondaga, Oswego, and the Lake Ontario, in Canada. London, 1743, 1751: Printed from J. Whiston and B. White (reprinted at Geneva, N.Y., 1895).

Beauchamp W.M.: The Iroquois Trail, or Foot-prints of the Six Nations, in Customs, Traditions, and History, in Which Are Included David Cusick's Sketches of Ancient History of the Six Nations, printed by Fayetteville, N.Y.: H.C. Beauchamp, 1892.

Beauchamp W.M.: Onondaga Customs. "Journal of American Folklore" 1888, Vol. 1(3), pp. 195-203. Manuscript, New York State Library, Albany.

Birket-Smith K.: Function and the False-faces: A Classification of Onondaga Masked Rituals and Themes. "Journal of American Folklore" 1966, Vol. 79(314), pp. 564-580, Manuscript, New York State, Library, The Oneidas.

Converse H.M.: Iroquois Masks. "Buffalo Express," October 18, 1899.

Converse H.M.: Myths and Legends of the New York State Iroquois, Ed. A.C. Parker. "New York State Museum Bulletin" 1908, Vol. 125. Albany.

Converse H.M.: The Seneca New-Year Ceremony and Other Customs. "Indian Notes" 1930, Vol. 7, pp. 68-86. New York: Museum of the American Indian.

Fenton W.N.: Iroquois Masks: A Living Tradition in the Northeast. In American Indian Art, from and Tradition: An Exhibition Organized by the Walker Art Center, the Indian Art Association, and the Minneapolis Institute of Art, 22 October-31 December, 1972. Minneapolis, 1972b, pp. $42-47$.

Fenton W.N.: Masked Medicine Societies of the Iroquois. In Annual Report of the Smithsonian Institution for 1940. Washington, D.C., 1941, pp. 397-430.

Fenton W.N.: Museum and Field Studies of Iroquois Masks and Ritualism. In Exploration and Field Work of the Smithsonian Institution in 1940, pp. 95-100. Washington, D C., 1941c.

Fenton W.N.: An Outline of Seneca Ceremonies at Coldspring Longhouse. In Yale University Publication in Anthropology 1936, Vol. 9, pp. 1-23.

Fenton W.N.: Review: Comments on Certain Iroquois Masks. Joseph Keppler. American Anthropologist 1942a, Vol. 44, pp. 118-119.

Fenton W.N.: Some Questions of Classification, Typology, and Style Raised by Iroquois Masks. In Transactions of the New York Academy of Science, 2d ser., 18. 1956, Vol. 18, pp. 347-357.

Hendry J.: Iroquois Masks and Maskmaking at Ondaga. Anthropological paper no. 74. "Bureau of American Ethnology Bulletin" 1964, Vol. 191, pp. 349-409. Washington, D.C.

JAMESON J.: Narratives of New Netherland (Contains Narrative of a Journey into the Mohawk and Oneida Country). Charles Scribner's Sons, New York 1909, pp. 135-157, 1634-1635.

Josef Niesyto's website, "A gallery of Iroquois masks." Fig. 1-14 [accessed: May 5, 2020], http:// josefniesyto.org/gallery/5/2/.

KePPLER J.: Comments on Certain Iroquois Masks. Contributions from the Museum of the American Indian. Heye Foundation 12, 1941, Vol. 13(4), pp. 1-40.

Lévi-Strauss C.: Drogi masek. Łódź 1985.

McGowan K., Rosse H.: Masks and Demons. Harcourt Brace, New York 1923.

Ritzenthaler R.E.: Iroquois False-face Masks. In Milwaukee Public Museum Publications in Primitive Art 3. pp. 1-71. Milwaukee 1969.

Rogers E.S.: Masks: The Many Faces of Man: An Exhibition Presented by the Division of Art and Archaeology of the Royal Ontario Museum, Toronto 1959.

Tuck J.A: Onondaga Iroquois Prehistory. Syracuse University Press, Syracuse 1971.

Wissler C.: The Lore of the Demon Mask. Natural History, New York 1928, Vol. 28(4), pp. 339-352. 